\title{
Evaluation of Hardness Parameters of TiCN Coating
}

\author{
František Botko ${ }^{1}$, Michal Hatala ${ }^{1}$, Pavol Beraxa ${ }^{1,2}$, Andrej Czán ${ }^{3}$, Darina Dupláková ${ }^{1}$, Ján Zajac ${ }^{1}$ \\ \{rantisek.botko@tuke.sk, michal.hatala@tuke.sk, pavol.beraxa@tuke.sk\} \\ Technical University of Kosice, Faculty of Manufacturing Technologies with a seat in Presov, \\ Bayerova 1, 08001 Presov, Slovakia ${ }^{1}$ \\ ŽP VVC, s.r.o., Kolkáreň 35,976 81 Podbrezová, Slovakia²
}

Faculty of Mechanical Engineering - University of Zilina, Univerzitna 1, 01026 Zilina - Slovakia ${ }^{3}$

\begin{abstract}
Presented article is focused on surface treatment technology depositing the thin, abrasion-resistant hard coatings on the surface of tools by CVD (Chemical Vapor Deposition) coating technology. To determine the appropriate coating layers and the substrate itself (tool material) is necessary to know the stress and deformation of the product in the forming process. In our case, after the determination of these parameters the tool (former) material Bohler S600 in combination with the application of TiCN coating by high temperature CVD process was selected. Experimental tests were performed to determine hardness. Tools with CVD coating have been used in real operating conditions in the production of seamless steel reducers.
\end{abstract}

Keywords: coating, steel S600, hardness, indentation

\section{Introduction}

Demands for the reliability and effectiveness of tools used in manufacturing processes increased with the advancement of technology and make up a considerable part of the total cost of the business undertaking [1].

Fulfillment of nowadays technical and economic parameters of manufacturing companies requires reliable and failure free operation of machines, devices and tools. Reliability is crucial factor to prevent negative effects such as reduction of product quality, increasing of technical downtime caused by tools wear or damage. Mentioned factors affect economic efficiency of company. Usage and wear type affect selection of appropriate coating taking in account physical and chemical properties. Coating properties are evaluated using measurement of micro and nanohardness, adhesion properties, thickness and surface roughness. Tribology properties of coated components are evaluated by ball-on-plate method which allows determination of friction coefficient [3].

CVD coating is nowadays wide spread coating technology and offers wide range of functional coating. Customer demands and new technologies research contribute to the enlargement of CVD coatings portfolio. Appropriately used CVD coating dramatically 
increases utility properties of tool, increases quality and reproducibility of manufacturing process and thus product [1] [2].

\section{Experimental material}

Experimental material used in presented research was selected wolfram-molybdenum high speed steel with business mark Böhler S600 (identification according to DIN: HS 6-5-2). Chemical composition of selected experimental material is listed in following table (Table 1.) [4] [5].

Table 1. Chemical composition of steel Böhler S600 [1]

\begin{tabular}{cccccccc}
\hline element & $\mathbf{C}$ & $\mathbf{S i}$ & $\mathbf{M n}$ & $\mathbf{C r}$ & $\mathbf{M o}$ & $\mathbf{V}$ & $\mathbf{W}$ \\
\hline \multirow{2}{*}{$(\boldsymbol{\%})$} & $0,80-$ & $\max$. & $\max$. & $3,80-$ & $4,50-$ & $1,50-$ & $5,50-$ \\
& 0,90 & 0,45 & 0,45 & 4,60 & 5,50 & 2,20 & 7,00 \\
\hline
\end{tabular}

Subsequent step of research was application of TiCN coating using CVD technology on selected substrate. Temperature of deposition was set on $1020^{\circ} \mathrm{C}$. Technologic procedure of CVD deposition consists of several steps, which are listed below [1]:

1. Coating $\mathrm{TiCN}-\mathrm{I}-$ coating time 90 minutes

$$
T=1010-1020{ }^{\circ} \mathrm{C}
$$

2. Coating TiCN - II - coating time 60 minutes

$$
T=1020^{\circ} \mathrm{C}
$$

3. Coating $\mathrm{TiC}$ - coating time 60 minutes

$$
T=1020^{\circ} \mathrm{C}
$$

4. Coating TiCN - II - coating time 60 minutes

$$
T=1020^{\circ} \mathrm{C}
$$

5. Coating TiCN - I - coating time 60 minutes

$$
T=1020^{\circ} \mathrm{C}
$$

6. Coating $\mathrm{TiN}$ - coating time 90 minutes $T=950{ }^{\circ} \mathrm{C}$

At mentioned temperatures is working chamber of coating device filled with mixture of TiCl4, N2, CH4 a H2 gases. Figure 1. shows CVD coating device. CVD coating (TiCN) used in presented research is characterized with properties listed in following table (Table 2.) [6].

Table 2. Several properties of TiCN coating

\begin{tabular}{cccc}
\hline $\begin{array}{c}\text { Micro hardness } \\
\text { HV 0,025 }\end{array}$ & $\begin{array}{c}\text { Thickness } \\
{[\boldsymbol{\mu m}]}\end{array}$ & $\begin{array}{c}\text { Friction } \\
\text { coefficient } \boldsymbol{f}\end{array}$ & $\begin{array}{c}\text { Coating } \\
\text { temperature }\left[{ }^{\circ} \mathbf{C}\right]\end{array}$ \\
\hline 4500 & $1-12$ & $0,5-0,6$ & 1020 \\
\hline
\end{tabular}




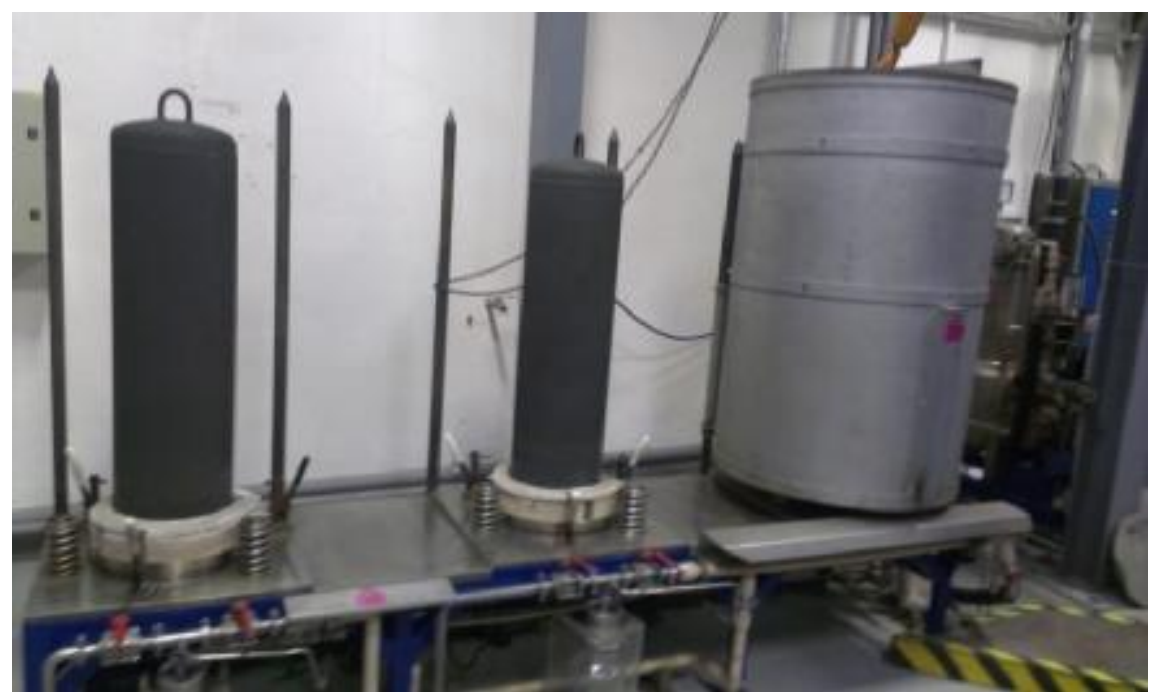

Fig. 1. Device used for application of CVD coating TiCN

Experimental samples were deposited by multilayer TiCN coating consisting of $\mathrm{TiN} / \mathrm{TiCN} / \mathrm{TiC}$ layers (Figure 2.)

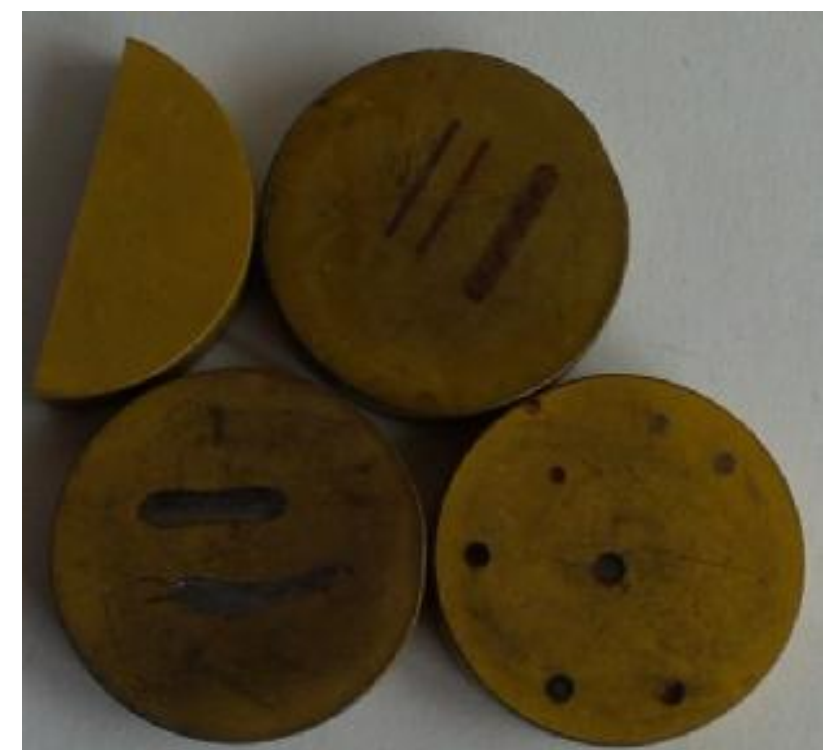

Fig. 2. Experimental samples

Experimental coating combines properties of individual layers TiN with excellent friction properties, TiCN with high wear resistance and $\mathrm{TiC}$ with excellent hardness.

Components optimal life time is ensured by additional polishing after coating on surface roughness $R a=0,1 \mu \mathrm{m}$. Final hardness $(58-62 \mathrm{HRc})$ is obtained by heat treatment process 
using vacuum hardening furnace after coating. Hardening process is performed after coating due to process parameters of CVD coating such as $1000^{\circ} \mathrm{C}$ temperature and 7 hours deposition time which affect structure of substrate.

Experimental samples were manufactured with diameter $20 \mathrm{~mm}$ and thickness $5 \mathrm{~mm}$.

\section{Evaluation of experiment}

Micro hardness testers use electromagnet or piezoelectric phenomena for step increasing load of Vickers indenter and inductive sensor for detection of indent depth. Layers hardness is indicated in GPa. Loading and unloading courses indicate elastic-plastic properties of material. Micro hardness HV can be calculated using equation (1).

$$
H_{v}=\frac{L_{\max }}{26,43 \cdot\left(h_{r}^{\prime}\right)^{2}}[G P a]
$$

Micro hardness was measured using micro hardness tester DuraScan - 20 with load range $98,1 \mathrm{mN}$ to $98,1 \mathrm{~N}$. Measurement was realized using Vickers method with maximal load of indenter $500 \mathrm{mN}(\mathrm{HV0}, 05)$. Hardness was measured in perpendicular direction to surface, in TiC layer which is contact layer with base material and in base material (substrate). Following figure (Figure 3.) shows indents in TiC layer and in base material.

As shown in Table 3., the highest values of hardness HV0,05 $=2150$ is measured perpendicular to surface of experimental sample, which is three times higher compared to base material.



Fig. 3.The HV0,05 microhardness measurement 
Table 3.Measured values of HV0,05 on samples with CVD TiCN coating

\begin{tabular}{|c|c|c|c|c|c|c|c|}
\hline \multirow{2}{*}{$\begin{array}{l}\text { Distance } \\
\text { from } \\
\text { surface } \\
{[\mu \mathrm{m}]}\end{array}$} & \multicolumn{6}{|c|}{ Measurement } & \multirow{2}{*}{ Location } \\
\hline & 1 & 2 & 3 & 4 & 5 & 6 & \\
\hline 30 & 701 & 721 & 727 & 721 & 714 & 708 & $\begin{array}{l}\text { Base material } \\
\text { crosscut - } 1\end{array}$ \\
\hline 8 & 1758 & 1811 & 1771 & 1811 & 1838 & 1820 & $\begin{array}{l}\text { CVD coating } \\
\text { crosscut (TiC } \\
\text { layer) - } 2\end{array}$ \\
\hline $\mathbf{0}$ & 2154 & 2112 & 2181 & 2174 & 2145 & 2132 & $\begin{array}{l}\text { CVD coating } \\
\text { perpendicular } \\
\text { to surface }\end{array}$ \\
\hline
\end{tabular}



Fig. 4. Graphical dependence of HV0,05 on distance from surface

Nanohardness measurements were performed in cooperation with IMR SAS Košice using Nanoindentation Tester NHT $^{2}$ from manufacturer CSM Instruments SA (Figure 5.) Nanoindentation measurement was performed using Berkovich three-sided diamond indenter. Principle and procedure is very similar to Vickers hardness test. Tetrahedral pyramid is thanks to the shape less sensitive to shock. Original Berkovich indenter was designed so that ratio between wall surfaces of pyramid and height was equal to Vickers indenter. For tetrahedral pyramid is angle of wall $60,03^{\circ}$.

Nanohardness value $H$ is determined by measurement of load and depth of indenter penetration. Figure 6. shows typical nanohardness curve. 
Following equation (2) expresses value of Berkovich nanohardness as ratio of load and surface of the $65,03^{\circ}$ pyramid:

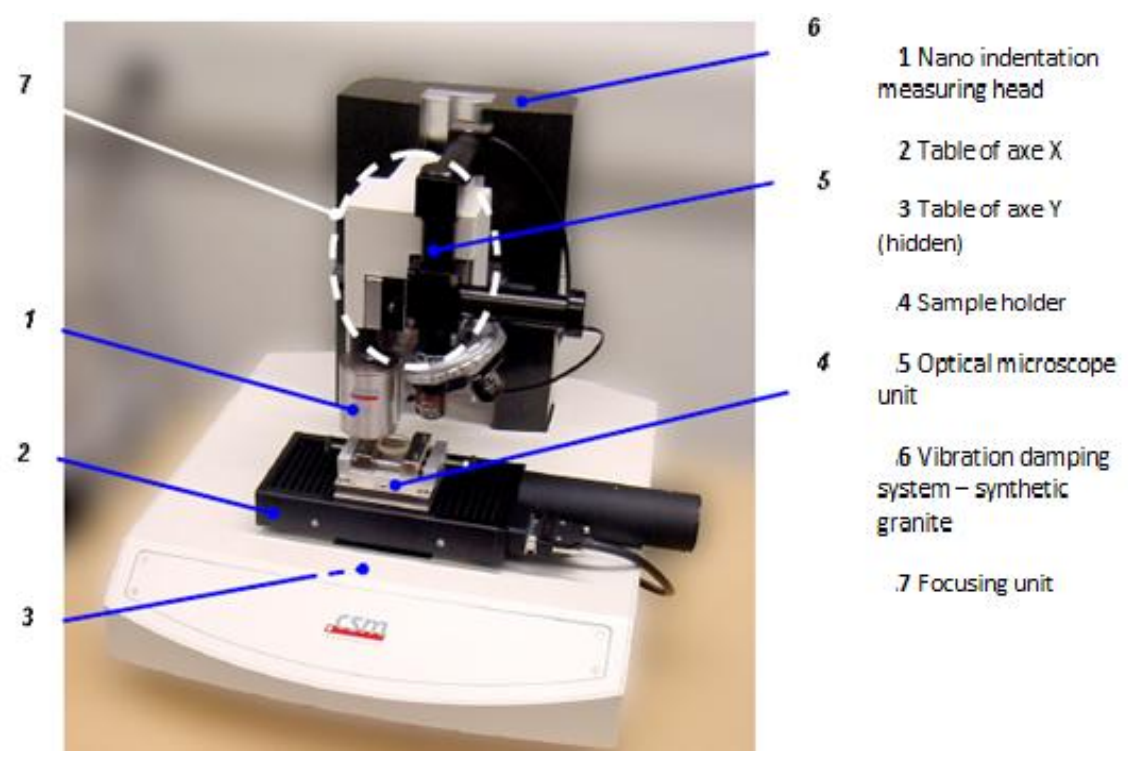

Fig. 5. Nanohardness tester

$$
H=1570 \times\left(W / l^{2}\right)
$$

Where:

$\mathrm{W}$

$l$

load $[\mathrm{kg}]$

depth of indent $[\mu \mathrm{m}]$

Nanohardness measurement was performed with load $250 \mathrm{mN}$. Loading force course is illustrated on picture below (Figure 7.)

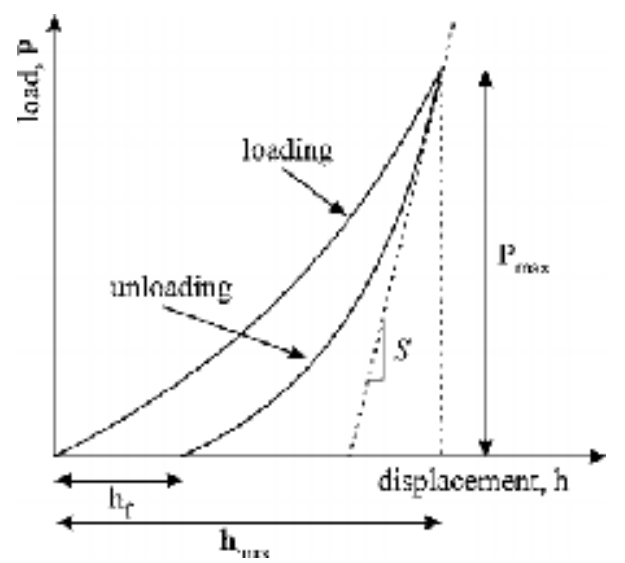

Fig. 6. Graphical representation of nanohardness curve [7] 


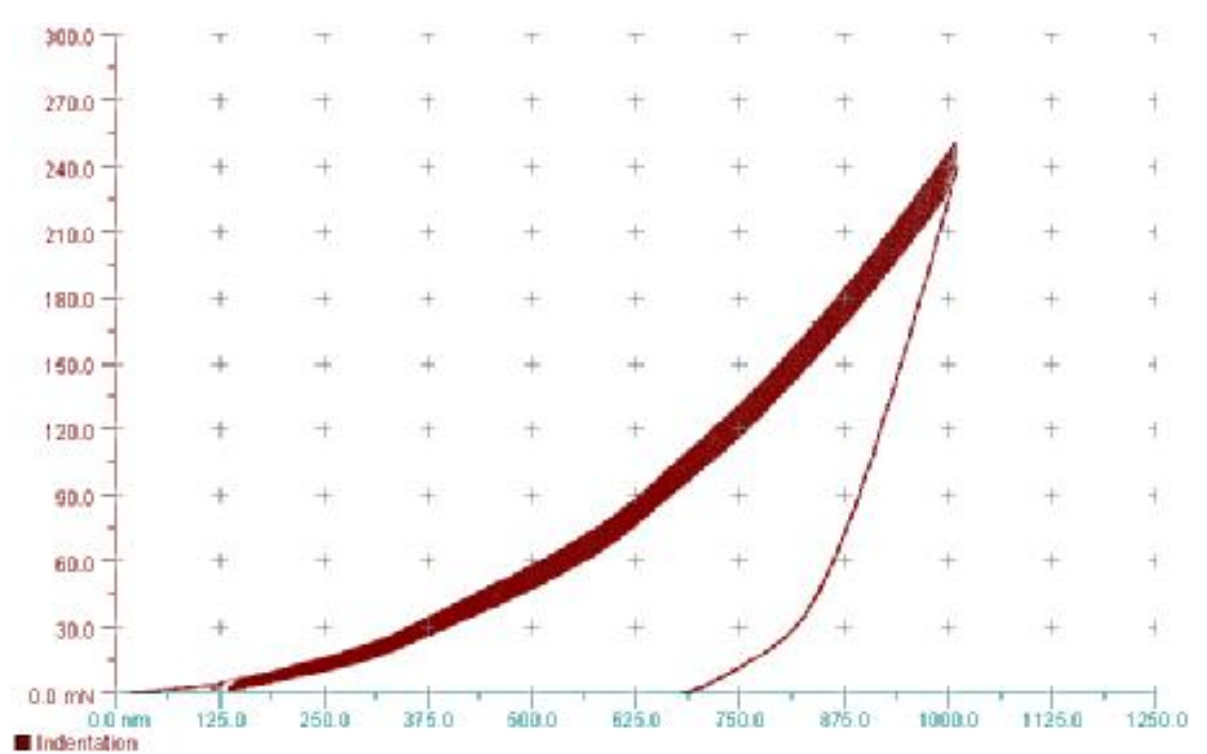

Fig. 7. Courses of nanohardness curves in dependence on depth of indent (load $250 \mathrm{mN}$ and depth $1 \mu \mathrm{m})$

Nanohardness value obtained as average of 20 measurements was 19,5 GPa and depth of indent circa $1050 \mathrm{~nm}$. Following figure (Figure 8.) shows shape of indent after nanohardness measurement using Berkovich indenter.

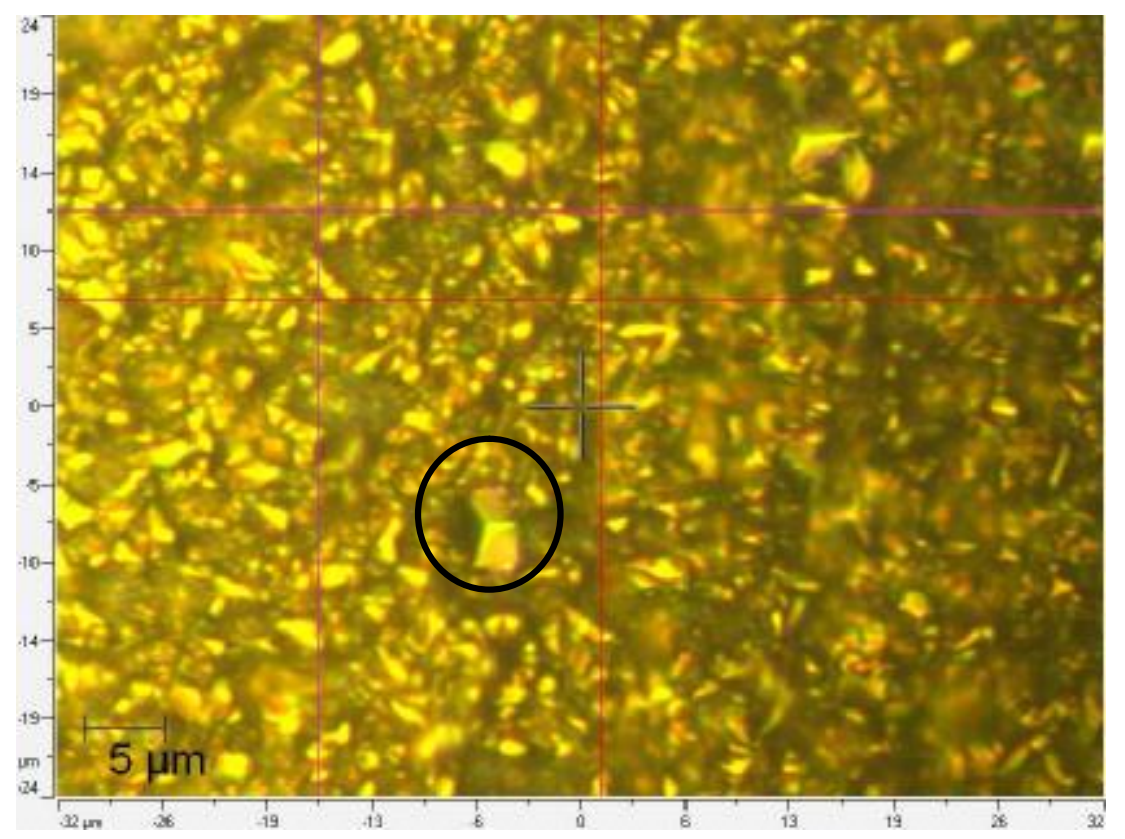

Fig. 8. Shape of indent for Berkovich diamond pyramid indenter 


\section{Conclusions}

Nano and micro hardness measurements proved capability of selected TiCN coating in configuration TiN/TiCN/TiC on S600 substrate for application in industrial conditions. Values measured using Vickers method on surface $2150 \mathrm{HV}$ and in depth $8 \mu \mathrm{m} 1850 \mathrm{HV}$ testify high hardness of selected coating. Form nanohardness point of view was observed hardness of coating and depth of penetration of indenter. Average value measured on TiCN coating using Berkovich method was $19,5 \mathrm{GPa}$, which is high hardness characteristic for wear resistant coatings. At the same time was confirmed requirement of maximal indenter penetration is equal to $1 / 10$ of coating thickness. Average depth of penetration measured on experimental samples was $1,05 \mu \mathrm{m}$.

Acknowledgments. This paper has been elaborated in the framework of the project APVV15-0696 and 039TUKE-4/2017 and in cooperation FVT TUKE with a seat in Presov and ŽP VVC Podbrezova under contract no.01/2014.

\section{References}

[1] Beraxa, P.: Implementation of cvd coating process for cold forming tools, Disertation thesis, p. 105 (2014)

[2] Bharat B., Xiaodong L.: Nanomechanical characterisation of solid surfaces and thin films. International Materials Reviews. Vol. 48, pp. 125 - 164 (2003)

[3] Beraxa, P., Domovcová, L., Parilák, L'.: Implementation of the CVD process for cold forming tools. Proceedings of 19th Conference on materials and technology, Portorož, Slovenia. ISBN 978-96192518-4-3 (2011)

[4] Dunne, F., Petrinic, N.: Introduction to Computational Plasticity. OXFORD University Press, ISBN 0-19-856826-6, p. 241 (2006)

[5] J. Zajac, D. Mital, S. Radchenko, et al.: Short-term Testing of Cutting Materials Using the Method of Interrupted Cut. Operation and Diagnostics of Machines and Production Systems Operational States II book series: Applied Mechanics and Materials. pp. 236-243 (2014)

[6] J. Zivcak, M. Petrik, R. Hudak, et al.: Embedded Tensile Strenght Test Machine FM1000-An Upgrade of Measurement and Control. Mechatronic systems and materials III. Book Series: Solid State Phenomena. pp. 657-662 (2009)

[7] Mussert, K. M., Vellinga, W. P., Bakker, A., Van Der Zwaag, S.: A nano-indentation study on the mechanical behaviour of the matrix material in an AA6061 - A12O3 MMC. Journal of material science. Vol. 37, pp 789 -794 (2002) 